\title{
AUTHOR INDEX FOR VOLUME 93
}

ADAMS, M. P.; Mathematical models of calcium and tight junctions in normal and reconstructed epidermis

ALJOUIEE, A. M.; see ZAÏMI, T.

AMRI, M., MKAOUAR, M. and WANNES, W.; Strongly $q$-additive functions and distributional properties of the largest prime factor

BACK, J. M.; Stefan problems for melting nanoscaled particles

BAHLEKEH, A. and MAHIN FALLAH, A.; Progress on the Auslander-Reiten conjecture

BERTIN, M. J.; see ZAÏMI, T.

BOLL, E. and PENNISTON, D.; The 7-regular and 13-regular partition functions modulo 3

BORWEIN, J. M. and GILADI, O.; Nearest points and delta convex functions in Banach spaces

BORWEIN, J. M. and SINNAMON, C. W.; A closed form for the density functions of random walks in odd dimensions

BUNDSCHUH, P. and VÄÄNÄNEN, K.; Arithmetic properties of infinite products of cyclotomic polynomials

BURKE, M.; Synthetic Lie theory

BUTTON, J., CHIODO, M. and ZERON-MEDINA LARIS, M.; Transversals as generating sets in finitely generated groups

CAO, T.; On the Brück conjecture

CAO, X. and CHOU, W.-S.; More constructions of approximately mutually unbiased bases

CHANG, S. J., CHOI, J. G. and KO, A. Y.; A translation theorem for the generalised analytic Feynman integral associated with Gaussian paths

CHEN, C. X.; Modelling of atherosclerotic plaque growth using fluid-structure interaction

CHIODO, M.; see BUTTON, J.

CHOI, J. G.; see CHANG, S. J.

CHOU, W.-S.; see CAO, X.

CHUNG, J. and RASSIAS, J. M.; On a measure zero stability problem of a cyclic equation

CUSIMANO, N.; Fractional models in space for diffusive processes in heterogeneous media with applications in cell motility and electrical signal propagation

DING, S.; see HUANG, Z.

DOLINKA, I., EAST, J. and MITCHELL, J. D.; Idempotent rank in the endomorphism monoid of a nonuniform partition

DRAGOMIR, S. S.; Buzano's inequality holds for any projection $\quad 504$

DUDEK, A. W.; On the number of divisors of $n^{2}-1 \quad 194$

EAST, J.; see DOLINKA, I. 
FERNÁNDEZ BONDER, J., PINASCO, J. P. and SALORT, A. M.; Eigenvalue homogenisation problem with indefinite weights

FERRAGUTI, A. and MICHELI, G.; On the Mertens-Cesàro theorem for number fields

GILADI, O.; see BORWEIN, J. M.

HAN, Q.; see LÜ, F.

HEMANTHKUMAR, B.; see MAHADEVA NAIKA, M. S.

400

HOÀNG, D. P.; Łojasiewicz-type inequalities and global error bounds for nonsmooth definable functions in o-minimal structures

HUANG, Z., PAN, J. M., DING, S. and LIU, Z.; Automorphism groups of selfcomplementary vertex-transitive graphs

HUI, F. K. C.; Mixing it up: new methods for finite mixture modelling of multispecies data in ecology

HUUSKO, J.-M.; Localisation of linear differential equations in the unit disc by a conformal map

JAFARIAN AMIRI, S. M., MADADI, H. and ROSTAMI, H.; On the probability of generating nilpotent subgroups in a finite group

KAKARIADIS, E. T. A. and PETERS, J. R.; Ergodic extensions of endomorphisms

KANEKO, M. and SAKATA, M.; On multiple zeta values of extremal height

KANG, S.-J.; Refined motivic dimension of some Fermat varieties

KIM, B.; A remark on tail distributions of partition rank and crank

KO, A. Y.; see CHANG, S. J.

KOSI-ULBL, I. and VUKMAN, J.; A note on $(m, n)$-Jordan derivations of rings and Banach algebras

KOVALEV, L. V.; Lipschitz retraction of finite subsets of Hilbert spaces

KREMPA, J. and STOCKA, A.; Addendum to 'On sets of pp-generators of finite groups'

LI, J.-Z.; Mazur-Ulam property of the sum of two strictly convex Banach spaces

LING, B. and LOU, B. G.; A 2-arc transitive pentavalent Cayley graph of $\mathrm{A}_{39}$

LIU, X.; Selected topics in spectral graph theory 511

LIU, Z.; see HUANG, Z. 238

LLORENS-FUSTER, E.; Orbitally nonexpansive mappings 497

LOU, B. G.; see LING, B.

LÜ, F., HAN, Q. and LÜ, W.; On unicity of meromorphic solutions to difference equations of Malmquist type

LÜ, W.; see LÜ, F.

LUO, Y. F.; see ZHANG, W. T.

MADADI, H.; see JAFARIAN AMIRI, S. M. 
MAHADEVA NAIKA, M. S., HEMANTHKUMAR, B. and SUMANTH BHARADWAJ, H. S.; Congruences modulo 2 for certain partition functions

MAHIN FALLAH, A.; see BAHLEKEH, A.

MARQUES, D., RAMIREZ, J. and SILVA, E.; A note on lacunary power series with rational coefficients

MEEMARK, Y.; see SUNTORNPOCH, B.

MICHELI, G.; see FERRAGUTI, A.

MITCHELL, J. D.; see DOLINKA, I.

MKAOUAR, M.; see AMRI, M.

MOORES, M. T.; Bayesian computational methods for spatial analysis of images

NAGOSHI, H.; Hypertranscendence of $L$-functions for $\mathrm{GL}_{m}\left(\mathbb{A}_{\mathbb{Q}}\right)$

OHNO, T. and SHIMOMURA, T.; Sobolev inequalities for Riesz potentials of functions in $L^{p(\cdot)}$ over nondoubling measure spaces

PAN, J. M.; see HUANG, Z.

PEATE, J.; Riesz transform estimates in the absence of a preservation condition and applications to the Dirichlet Laplacian

PELLEGRINI, M. A.; The (2,3)-generation of the classical simple groups of dimensions 6 and 7

PENNISTON, D.; see BOLL, E.

PETERS, J. R.; see KAKARIADIS, E. T. A.

PINASCO, J. P.; see FERNÁNDEZ BONDER, J.

RAMIREZ, J.; see MARQUES, D.

RASSIAS, J. M.; see CHUNG, J.

REZA SALARIAN, M.; Finite symmetric graphs with 2-arc-transitive quotients: affine case

ROSTAMI, H.; see JAFARIAN AMIRI, S. M.

SAKATA, M.; see KANEKO, M.

SALORT, A. M.; see FERNÁNDEZ BONDER, J.

SANINA, E.; Statistics of wave kinematics in random directional wave fields

SHPARLINSKI, I. E.; Systems of congruences with products of variables from short intervals

SHRAVAN KUMAR, N. and SIVANANTHAN, S.; Characterisation of the Fourier transform on compact groups 
SUNTORNPOCH, B. and MEEMARK, Y.; Cayley graphs over a finite chain ring and gcd-graphs

SUTHERLAND, N.; Algorithms for Galois extensions of global function fields

TĂRNĂUCEANU, M.; The subgroup commutativity degree of finite $P$-groups

TEHSEEN, N.; Geometric symmetry techniques for partial differential equations

THAO, N. H.; Regularity properties in variational analysis and applications in optimisation

VÄÄNÄNEN, K.; see BUNDSCHUH, P.

VAN DEN DUNGEN, K.; Lorentzian geometry and physics in Kasparov's theory

VUKMAN, J.; see KOSI-ULBL, I.

WANG, Y.; Filtered polynomial approximation on the sphere

WANNES, W.; see AMRI, M.

177

XUE, Z. Q.; Fixed points theorems for generalised weakly contractive mappings 321

YANG, Y. L. and ZHANG, D. Y.; Two optimisation problems for convex bodies

YOU, C.; Group action preserving the Haagerup property of $C^{*}$-algebras

YOU, C.; Model selection and estimating degrees of freedom in Bayesian linear and linear mixed effect models

ZAÏMI, T., BERTIN, M. J. and ALJOUIEE, A. M.; On number fields without a

unit primitive element
ZARRIN, M.; On noncommuting sets and centralisers in infinite groups

ZERON-MEDINA LARIS, M.; see BUTTON, J.

ZHANG, D. Y.; see YANG, Y. L.

ZHANG, W. T. and LUO, Y. F.; A sufficient condition under which a semigroup is nonfinitely based

ZHANG, Z.; see ZHOU, Y.

ZHOU, Y., ZHANG, Z. and LIU, C.; On isometric representation subsets of Banach spaces

ZIVARI-KAZEMPOUR, A.; A characterisation of 3-Jordan homomorphisms on Banach algebras 


\section{INFORMATION FOR AUTHORS}

The Bulletin of the Australian Mathematical Society aims at quick publication of original research in all branches of mathematics. To ensure speedy publication, only articles which are sufficiently well presented, able to be published without revision, and which are judged by the Editor (often in consultation with an Associate Editor) to be competitive are refereed. This policy is in the interests of authors, as a quick rejection is better than a slow rejection. The Bulletin receives more than five times the material that can be published, therefore there are many commendable papers not accepted. Editorial decisions on acceptance or otherwise are taken quickly, normally within a month of receipt of the paper. Papers are accepted only after peer review.

Manuscripts are accepted for review with the understanding that the same work is not concurrently submitted elsewhere. For a paper to be acceptable for publication, not only should it contain new and interesting results, but also

(i) the exposition should be clear and attractive, and

(ii) the manuscript should be in publishable form, without revision.

Further information regarding these requirements may be found through our website www.austms.org.au/Bulletin. Authors are asked to avoid, as far as possible, the use of mathematical symbols in the title.

Articles should be prepared in $\mathrm{ET}_{\mathrm{E}} \mathrm{X}$ using $\mathcal{A}_{\mathcal{M}} \mathcal{S}$-LTEX packages and submitted as a PDF file via our journal management system, at www.austms.org.au/Publications/Submissions/BAustMS. This permits authors to track their papers through the editorial process. Recent versions of $\mathrm{T}_{\mathrm{E}} \mathrm{X}$ are able to produce PDF files directly. A LTTEX class file for the Bulletin can be downloaded from the website. Authors who need assistance may email the secretary of the Bulletin at editor@bulletin.austms.org.au.

Authors are advised to keep copies of all files of the submitted article; the Bulletin will not accept responsibility for any loss.

\section{EDITORIAL POLICY}

1. References. Arrange references alphabetically (by surname of the first author) and cite them numerically in the text. Ensure the accuracy of the references: authors' names should appear as in the work quoted. Include in the list of references only those works cited, and avoid citing works which are in preparation or submitted. Where the work cited is not readily accessible (for example, a preprint) a copy of the article should be included with your submission.

\section{Abstracts.}

1. Each paper must include an abstract of not more than 150 words, which should contain a brief but informative summary of the contents of the paper, but no inessential details.

2. The abstract should be self-contained, but may refer to the title.

3. Specific references (by number) to a section, proposition, equation or bibliographical item should be avoided.

3. Subject Classification and Key Words. Authors should include a few key words and phrases and one or more classification numbers, following the American Mathematical Society 2010 Mathematics Subject Classification for all codes. Details of this scheme can be found on the web at www.ams.org/msc.

4. Abstracts of PhD Theses. The Bulletin endeavours to publish abstracts of all accepted Australasian $\mathrm{PhD}$ theses in mathematics. One restriction, however, is that the abstract must be received by the Editor within six months of the degree being approved.

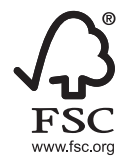

This journal issue has been printed on FSC-certified paper and cover board. FSC is an independent, non-governmental, not-for-profit organisation established to promote the responsible management of the world's forests. Please see www.fsc.org for information. 


\section{Table of Contents}

Cayley graphs over a finite chain ring and gcd-graphs

Suntornpoch, B. \& Meemark, 1 .

Systems of congruences with products of variables from short intervals

Shparlinski, I. E.

A note on lacunary power series with rational coefficients

Marques, D., Ramirez, f. \& Silva, E.

Arithmetic properties of infinite products of cyclotomic polynomials

Bundschuh, P. \& Väänänen, $K$.

Hypertranscendence of $L$-functions for $\mathrm{GL}_{m}\left(\mathbb{A}_{\mathbb{Q}}\right)$

Nagoshi, $H$.

Congruences modulo 2 for certain partition functions

Mahadeva Naika, M. S., Hemanthkumar, B. \& Sumanth Bharadwaj, H. S.

The 7-regular and 13-regular partition functions modulo 3

Boll, E. \& Penniston, $D$.

On number fields without a unit primitive element

Zaïmi, T., Bertin, M. J. E Aljouiee, A. M.

Progress on the Auslander-Reiten conjecture

Bahlekeh, A. \& Mahin Fallah, A.

A 2-arc transitive pentavalent Cayley graph of $\mathrm{A}_{39}$

Ling, B. \& Lou, B. G.

On the probability of generating nilpotent subgroups in a finite group Jafarian Amiri, S. M., Madadi, H. \& Rostami, $H$.

A sufficient condition under which a semigroup is nonfinitely based

Zhang, W. T. \& Luo, Y. F.

Characterisation of the Fourier transform on compact groups

Shravan Kumar, N. E. Sivananthan, $S$.

Mazur-Ulam property of the sum of two strictly convex Banach spaces

$L i$, J.-Z.

On isometric representation subsets of Banach spaces

Zhou, Y., Zhang, Z. \& Liu, C.

Orbitally nonexpansive mappings

Llorens-Fuster, $E$.

Buzano's inequality holds for any projection

Dragomir, S. S.

\section{Abstracts of $\mathrm{PhD}$ Theses}

Selected topics in spectral graph theory

Liu, $X$.

Algorithms for Galois extensions of global function fields

Sutherland, $\mathcal{N}$.

Synthetic Lie theory

Burke, $M$

Fractional models in space for diffusive processes in heterogeneous media with applications in cell motility and electrical signal propagation

Cusimano, $\mathcal{N}$.

Riesz transform estimates in the absence of a preservation condition and applications to the Dirichlet Laplacian

Peate, J.

Regularity properties in variational analysis and applications in optimisation

Thao, N. $H$.

Author Index for Volume 93

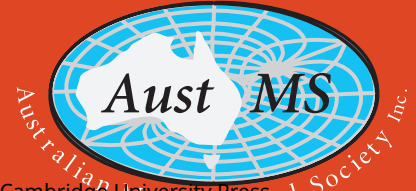

